Sección Documentos

\title{
San Miguelito de Soyaló, una caja parlante
}

\author{
Miguel Lisbona Guillén
}

\section{Introducción}

L as cajas parlantes no son un tema nuevo en la literatura antropológica chiapaneca, como tampoco lo son las referencias a otros elementos de la simbología religiosa que tienen la capacidad de comunicarse con los seres humanos o de interceder por ellos para la resolución de algún tipo de problema: cruces o imágenes sagradas. Su sabida existencia o los análisis hasta ahora realizados no significan que su presencia actual deje de inquietar a los que por interés o casualidad se acercan a ellas. Incluso la mayor referencia chiapaneca de los últimos años en los medios de comunicación nacionales e internacionales, el subcomandante Marcos, fue equiparado por Yvon Le Bot (2002) con ellas: "Marcos es un mediador, un puente, un vocero, como los «santos parlantes» de las antiguas rebeliones mayas".

La caja de referencia en este texto se encuentra todavía en la cabecera municipal de Soyaló, pueblo ubicado en la confluencia del Altiplano Central y las montañas del norte del estado de Chiapas, México, en

Miguel Lisbona Guillén, doctor en Antropología Social, PROIMMSE-IIA, Universidad Nacional Autónoma de México. Correo electrónico: mlisbona@ servidor.unam.mx lo que es hoy la región política Centro (I), un paso obligado de comunicación entre las capitales de los estados de Chiapas y Tabasco si se toma la antigua carretera. Este municipio, de elevados índices de marginación y con una población mayoritariamente católica, celebra como principal santo a San Miguel Arcángel, a quien está dedicada su parroquia, misma advocación que la caja parlante ostenta.

Si arriba se mencionaba que las cajas parlantes inquietan, hay que asegurar que esa misma inquietud, aunque de distinto signo y temporalidad por supuesto, se puede observar en dos documentos procedentes de artículos periodísticos aparecidos en 1937 (Chiapas Nuevo) y 1938 (Alborada); periódicos ligados a la incipiente estructura política surgida de la Revolución Mexicana, en concreto al Partido Nacional Revolucionario (PNR) y a los órganos sindicales que se estaban definiendo, y cuyas estructuras corporativas han llegado hasta nuestros días.

El contenido de los artículos, aunque publicados con más de un año de diferencia, gira alrededor de una misma problemática, la falsedad de los poderes taumatúrgicos de la caja parlante y su imagen, así como la explotación que de tal circunstancia efectúan las personas encargadas de custodiarla. Los ataques vertidos en los periódicos se producen en un periodo 
posrevolucionario nada ajeno a los últimos estertores del anticlericalismo que definió dicho periodo. Sin embargo, antes de entrar en ese aspecto hay otros dos que deben destacarse a la hora de considerar la presencia de las cajas parlantes, y ellos serán los que estructuren la presentación de los documentos en cuestión. El primero, es la misma existencia histórica y registro antropológico de las cajas parlantes; mientras el segundo se refiere a sus poderes curativos, cuestiones ambas que remiten, como se expresó líneas arriba, al contenido peyorativo de los documentos aquí reproducidos.

\section{Imágenes que hablan}

En la revisión que efectúa Amos Megged (2008: 173) de diccionarios coloniales, en concreto de los textos de Ara sobre la lengua tzeltal en el actual territorio de Chiapas, dicho autor menciona como posibles "santos parlantes" una de las entradas registrada en lengua indígena, algo que no le parece extraño al destacar la referencia directa que existe en el Popol Vuh de elementos sagrados parlantes o los posteriores ejemplos que la literatura antropológica se ha encargado de mostrar. Para el caso chiapaneco es, sin duda, Victoria Reifler Bricker quien efectuó la síntesis más extensa de las referencias históricas, pero sobre todo etnográficas, acerca de los santos parlantes. Además de señalar su carácter taumatúrgico, el cual recibirá mayor atención en el siguiente apartado, destaca en su repaso etnográfico las diversas posibilidades de presentación de estos objetos de culto, al poder ser cuadros de un santo, imágenes católicas o incluso piedras (Reifler Bricker, 1989: 319). Uno de los aspectos que destaca la autora es la posibilidad de que los santos parlantes puedan estar tanto en manos indígenas como ladinas, siendo el ejemplo más nítido de estas últimas la caja parlante de Soyaló, aunque no sea la única. Tampoco es ajena la existencia de tales cajas allende las fronteras del mundo maya donde Reifler Bricker parece ceñirlas, como quedó ejemplificado en el artículo que sobre tal temática publicaron Laureano Reyes y Susana Villasana
(1991: 95-112) en referencia a lo ocurrido en un poblado del municipio de Ixtacomitán, en la tierra zoque, donde se encontraba una caja parlante de San Miguelito bajo la custodia de un "mestizo".

Las interpretaciones vertidas sobre las cajas parlantes, que no serán abordadas en estas páginas, remiten con claridad al pasado, aunque seguramente la presencia de elementos de culto que se comunican con sus interlocutores humanos tiene en el siglo XIX hitos de relevancia entre los mayas; las cruces parlantes que guiaban a los líderes religiosos de la guerra de castas en la península de Yucatán son uno de ellos, por su trascendencia política y temporal, así como también lo fue para el territorio de los Altos de Chiapas la rebelión indígena de 1867 - mal llamada guerra de castas (Rus, 2004: 145-174) - , donde "piedras o estatuillas de arcilla [...] se comunican mediante golpes o, en algunos casos, hablando directamente" (Reifler Bricker, 1989: 321); algo similar a un oráculo en palabras de Andrés Medina (1983: 19). Lo que dichas piedras o figuras comunicaban a los intermediarios no parece claro, y en buena medida la historiografía construida ante el temor de futuras rebeliones indígenas marca la importancia dada a estos símbolos parlantes, que en muchos casos pudieron tratar aspectos taumatúrgicos alejados de cuestiones políticas.

\section{El poder de sanar o enfermar}

Serge Gruzinski, al explorar lo que denomina idoloclastia de los conquistadores a su llegada al Nuevo Mundo, destaca cómo la destrucción de los ídolos americanos fue entendida como una "espectacular descontaminación", misma que no podía eliminar el papel de las imágenes, sino de los considerados ídolos, puesto que los militares primero, y los evangelizadores después impusieron la imaginería católica (Gruzinski, 2003: 57-58).

Es decir, las imágenes cristianas debían ser "instrumentos del recuerdo y de la memoria" para evitar posibles confusiones alegóricas (Gruzinski, 2003: 75), 
tan propicias cuando de imaginería religiosa se trata. Para el historiador francés, pese al esfuerzo realizado por los conquistadores, triunfó la piedad barroca en tierras americanas. Piedad que dotaba a las imágenes de una eficacia simbólica cercana al milagro y al poder taumatúrgico (Gruzinski, 2003: 109). Esta cualidad taumatúrgica inscrita en lo considerado sagrado, cualquiera que sea su origen o adscripción religiosa, tiene un claro antecedente de estudio en la obra clásica de Marc Bloch, Los Reyes Taumaturgos, donde la condición de "personajes sagrados" ostentada por los reyes de la baja edad media les permitía la sanación, o al menos esa era la creencia, a través de la imposición de manos. Por lo tanto, los "reyes de Francia e Inglaterra pudieron convertirse en médicos milagrosos porque eran ya, desde hacía tiempo, personajes sagrados" (Bloch, 1993: 59).

Sin definir la procedencia de estas cualidades, lo que parece claro es que afirmar el carácter sagrado de una imagen o un ser humano, intercambiables figuras en muchos casos si se siguen las referencias antropológicas sobre dicha temática, significa, como lo advirtió perfectamente Bloch, decir "apto para curar" (Bloch, 1993: 80). Estas cualidades entre santos de origen medieval son constantes en la geografía católica de la vieja Europa, y en estas páginas sólo se ejemplifica con uno de ellos por tener la misma advocación, la de San Miguel. Se trata de una imagen ubicada en el municipio de Aralar, en la Navarra hispana, que desde el siglo XI es relacionada con la salud de seres humanos, animales, casas y campos, hecho que en la actualidad permanece con las visitas de enfermos a su santuario o mediante una "romería al revés", puesto que durante cuatro meses la imagen del santo recorre diversas localidades occidentales de Navarra (Otermin, 2004: 630).

Las cajas parlantes registradas por la etnografía chiapaneca están dotadas también de este carácter taumatúrgico, aunque pueden invertir sus acciones convirtiéndose en causantes de daño, situación comprensible si se piensa que quien ostenta el poder de sanar lo tiene también para causar el mal. Una ambigüedad que aparece en la etnografía cuando se refiere a objetos o imágenes sagradas, como percibió bien Jane Collier con respecto a las cajas parlantes de Zinacantán (Collier, 1995: 145). A pesar de ello, la clásica etnografía sobre Chiapas referida al tema, que resumió Reifler Bricker como ya se señaló en párrafos precedentes, mostraba otras vertientes de análisis, como lo son las distintas relaciones de la población y las autoridades con las cajas. En municipios como San Andrés Larráinzar o San Pedro Chenalhó, la custodia de las mismas se encontraba en manos de miembros del sistema de cargos religiosos del municipio, algo interpretado como un reforzamiento de la estructura religiosa local, mientras que en Zinacantán sus poseedores eran ajenos a la jerarquía religiosa, con lo cual desafiaban la autoridad vigente en tal materia (Reifler Bricker, 1989: 320-321).

A lo anterior y al carácter taumatúrgico de las cajas parlantes le siguen muchas otras posibilidades de análisis respecto a su papel en los lugares donde ejercen su influencia, sin embargo, los documentos con los que se ejemplifica este texto tienen una nítida decantación hacia esa última característica, como se observará en el siguiente apartado.

\section{Temor a las imágenes y políticas higienizadoras en la posrevolución}

Para quienes leyeran en alguna ocasión el libro de Graham Greene, Caminos sin ley, habrá resultado extraño que hasta ahora no se mencionara su referencia a San Miguelito de Soyaló —escrito "Sanoyo" en el libro-, puesto que el autor inglés dedica un apartado del viaje efectuado en tierras del sur de México, en el año 1938, a la caja parlante que ocupa la atención de este texto. El narrador señaló con precisión lo que molestaba a las autoridades mexicanas de aquellos años: el posible "renacimiento religioso", por lo que la acción gubernamental se había decantado por mandar "soldados para apoderarse del santo, pero no habían conseguido capturarlo". El mencionado renacimiento religioso, más 
bien provocado por la presencia de una imagen que condensaba la atención de la población local, estaba relacionado, como era de esperarse, con su carácter taumatúrgico: "Recomienda remedios; algunos son remedios indígenas, y otros las últimas medicinas de patente de la capital".

Es decir, Graham Greene había observado algo similar a lo descrito por los documentos que aparecen al final de este texto, por ejemplo su forma de estampilla: "parecería que no es más que una tarjeta postal" (Greene, 1996: 216); al mismo tiempo que relataba lo que los documentos adjuntos advierten, en forma de referencia de un informante:

El hombre de la cantina dijo que San Miguelito ya no estaba en Sanoyo [Soyaló]; habían mandado a un médico de Tuxtla, que dijo que todo el asunto era una cuestión de autosugestión, y se habían llevado el santo a un museo de la ciudad de México (Greene, 1996: 217).

Esta última parte no corresponde a lo expresado en los documentos, y la mala impresión que tenía el escritor inglés de la gente del país que visitaba le hizo averiguar por sí mismo lo que ocurría con la caja parlante en cuestión, especialmente por ser un reconocido católico.

Montado en un coche de alquiler con chofer se dirigió a Soyaló para constatar la existencia del santo parlante. Las degradantes descripciones de las personas que se encontraban en la casa de la familia que custodiaba el santo no le impidieron narrar de nuevo la fallida sustracción por parte de las autoridades públicas chiapanecas de la caja, al haber sido escondido el santo, de la misma forma que aportó un dato etnográfico nuevo, el control de las sanaciones del santo a través de la expedición de "certificados de curaciones", donde, sin mencionar a la imagen sagrada, se afirmaba haber obtenido la curación - a pesar de estar diagnosticado como "incurable" - a través de los remedios otorgados por el custodio del santo parlante (Greene, 1996: 221).
La extrañeza del fenómeno que estaba observando facilitó que diera una descripción de la caja parlante de Soyaló: "una de esas cajas de té victorianas",

divididas en dos compartimentos. Uno de los compartimentos estaba vacío; en el otro habían pegado una capillita tallada, y en el fondo una estampita de San Miguel [...]. La caja de té estaba llena de bolitas de papel plateado, de colores, y entre éstas asomaba un clavo, y en la punta del clavo una cabecita hueca, hecha, supongo, de plomo, como un soldado de juguete. Evidentemente, no era la cabeza de San Miguel, era la cabeza de una mujer; de cabello ondulado a la griega, una cabeza de camafeo [...]. No era el decorado de un milagro; había en todo esto algo de astuto, de aficionado (Greene, 1996: 222).

Descripción que no coincide con la otorgada en el primer documento aquí presentado, donde dice tratarse de "una copia fotostática de un niño de Atocha, como de siete centímetros de largo por cuatro de ancho, dentro de un camarín de madera, y que el público ha dado en llamar San Miguelito". A pesar de estas diferencias, los dos documentos coinciden en otorgar a Guadalupe Urbina y a su sobrino, Rodolfo Urbina, el control de la caja parlante, además de señalar la necesaria intervención de las autoridades estatales para evitar el incremento de fanáticos religiosos, así como el consecuente problema sanitario por ejercer la medicina fuera de los cauces legales.

Lo que los artículos periodísticos plantean está más allá de una simple cuestión sanitaria o de una reacción lógica en un periodo de acendrado anticlericalismo, en el fondo el problema que vislumbran se encuentra en la eficacia simbólica de las imágenes sagradas, cualquiera que sea su presentación o las acciones que realice.

La referencia al "santito médico" o las explicaciones científicas sobre las enfermedades y su curación que se expresan en los documentos parecen estar dirigidas a proponer una catarsis racional frente a una "imagen a 
la que se le atribuía facultades humanas". Lo anterior introduce de lleno el problema de la higienización social de prácticas consideradas retrógradas y arcaicas; es por ello que tal higienización estaba ligada a un supuesto pensamiento lógico, aquel que consideraba imposible circunscribir lo divino, por ser inmaterial, a cualquier forma material de presentación. Esta circunstancia era la que debía evitarse, puesto que la condensación de lo divino en el objeto se convierte en un mecanismo propio de la alegoría, tropo vital considerado un irracionalismo por sus detractores (Freedberg, 1989: 84-88).

La lucha del anticlericalismo posrevolucionario, principalmente, quiso otorgar explicaciones científicas a fenómenos que se movían bajo otra lógica de comprensión y expresión, ${ }^{1}$ y las cajas parlantes respondían perfectamente al poder de la alegoría representada por las imágenes consideradas sagradas. El peligro de las mismas estriba en su equiparación o posibilidad de intercambio con las actividades humanas, y por ende con sus facultades, como el primero de los documentos no deja de señalar en dos ocasiones. La persecución al santo parlante de Soyaló, al igual que fueron perseguidos con posterioridad por las autoridades ladinas de San Cristóbal de Las Casas los santos parlantes de municipios indígenas de los Altos de Chiapas (Collier, 1995: 271-272), implica una estrategia para encauzar a principios supuestamente científicos las formas de observar la realidad mediante un razonamiento analógico puesto en marcha por la alegoría desencadenada gracias a la imagen. Ésta se convierte en lo que representa: una especie de "fusión de signo y significado" (Freedberg, 1989: 49-50).

El carácter de engaño resaltado en los documentos, expresado también como necesidad de evitar mixtificaciones en boca de las autoridades sanitarias legalmente constituidas, está relacionado con la imposibilidad de controlar las formas de relación con las imágenes y la actuación de las personas que les otorgan poder. No hay más que verlo en el intento de control de la expansión de las cajas parlantes por otros territorios de la geografía chiapaneca, donde sorprende la mención al que fuera sacerdote ortodoxo en Chiapas, José Ramírez, como uno de los causantes de la misma, aunque a finales de 1934 había quemado los hábitos públicamente (Lisbona, 2008: 314-315); o la referencia a José Rachit [sic] de Tapilula, persona todavía recordada en dicho municipio en la actualidad por su labor terapéutica.

Es decir, los documentos no sólo muestran la existencia de las cajas parlantes en Chiapas, destacando una de las más conocidas en su territorio, sino que ponen sobre la mesa de discusión las circunstancias históricas que las propician, mismas que demuestran el temor causado por las relaciones con lo sagrado, que cuestionan las formas institucionalizadas de religiosidad o el pensamiento científico que se quería imponer como único e infalible, a pesar de todos los errores que en sus explicaciones del comportamiento humano y su sociedad se divulgaron en aquellos años. Temor en forma de ataque vivido en el periodo del que surgen los documentos, pero que se ha prolongado hasta nuestros días a través de las diatribas contrarias a dichas prácticas lanzadas desde la Iglesia católica o en el seno de los grupos evangélicos. En definitiva, los artículos periodísticos trascienden su contenido concreto ceñido a la caja parlante de San Miguelito en Soyaló para mostrar que el papel de las imágenes merece un análisis científico más allá de la simple representación que se les otorga desde las instituciones religiosas y políticas.

\section{Documentos}

1. "La Verdad del Santito Milagroso", en Chiapas Nuevo, Periódico de Acción Político-Sociale Informativo. Órgano del Comité de Estado del PNR, núm. 20, Tuxtla Gutiérrez: 17 de enero de 1937, pp. 3-6.

2. Camacho, J. Erasmo (1938), "La Farsa de «San Miguelito»", en Alborada, Órgano de la Federación Regional Revolucionaria del Trabajo, núm. 32, Tuxtla Gutiérrez: 22 de octubre de 1938, p. 2. 


\section{Notas}

${ }^{1}$ Las diatribas contra prácticas sanitarias consideradas retrógradas no se ceñían al centro de Chiapas, también se mostraron para lugares como el Soconusco. En la sección llamada "cartas a los lectores" aparece el siguiente texto: "Es una verdadera desgracia que en una ciudad de la categoría de Tapachula existan aún individuos que vivan de la credulidad de incautos que se ponen en sus manos para ser curados de su salud o de los llamados 'males echados' [...]. Pero lo peor del caso es que estos llamados 'Brujos' o 'Chimanes' ostentan flamantes rótulos en los que se dicen autorizados por el Departamento de Salubridad para Ejercer la Medicina sin título, cuando es público y notorio que no hacen otra cosa más que curar por medios y sistemas curativos que acarrean gravísimos perjuicios a la salud [...]. A este respecto hay que recordar que en el Centro del Estado se ha hecho con satisfactorios resultados, una enérgica batida y cruzada en contra de los brujos y chimanes [sic]" (Archivo Histórico del Estado, Hemeroteca, Chiapas, núm. 214, Tuxtla Gutiérrez: 11 de mayo de 1933, p. 5).

\section{Bibliografía}

Bloch, Marc (1993) [1924], Los Reyes Taumaturgos, México: F.C.E.

Collier, Jane (1995) [1973], El Derecho Zinacanteco. Procesos de disputar en un pueblo indígena de Chiapas, México: UNICACH-CIESAS.

Freedberg, David (1989), El poder de las imágenes. Estudios sobre la historia y la teoría de la respuesta, Madrid: Cátedra.
Greene, Graham (1996) [1953], Caminos sin ley, México: CONACULTA.

Gruzinski, Serge (2003), La guerra de las imágenes. De Cristóbal Colón a "Blade Runner", México: F.C.E.

Le Bot, Yvon (2002), "Toledo y los zapatistas: elogio al silencio", en http://www.jornada.unam. $\mathrm{mx} / 2002 / 06 / 28 / 018$ alpol.php?origen=opinion.html [28 de junio de 2002].

Lisbona Guillén, Miguel (2008), Persecución religiosa en Chiapas (1910-1940). Iglesia, estado y feligresía en el periodo revolucionario, México: PROIMMSE/IIA/UNAM.

Medina Hernández, Andrés (1983), "Los grupos étnicos y los sistemas tradicionales de poder en México", en Nueva Antropología, vol. V, núm. 20, México, pp. 5-29.

Megged, Amos (2008) [1996], Cambio y persistencia indígena en Chiapas, 1521-1680, México: CIESAS-Univesidad de Haifa.

Otermin Elcano, Marisol (2004), "La faceta taumatúrgica de San Miguel de Aralar", en R. Jimeno y J.I. Homobono (eds.), Fiestas, rituales e identidades, Cuadernos de Antropología y Etnografía/Zainak, núm. 26, Guipuzcoa, pp. 629-637.

Reifler Bricker, Victoria (1989) [1981], El Cristo Indígena, El Rey Nativo. El sustrato histórico de la mitología del ritual de los mayas, México: F.C.E.

Reyes Gómez, Laureano y Susana Villasana Benítez (1991), "San Miguelito y la caja parlante. El caso de un poblado de damnificados del volcán Chichonal", en Anuario CEI, vol. III, Tuxtla Gutiérrez: UNACH, pp. 95-112.

Rus, Jan (2004) [1995], "¿Guerra de castas según quién?: Indios y ladinos en los sucesos de 1869", en Viqueira Albán, Juan Pedro y Mario Humberto Ruz (eds.), Chiapas, los rumbos de otra historia, México: CEMCA/ IIFL/UNAM-CIESAS, pp. 145-174. 


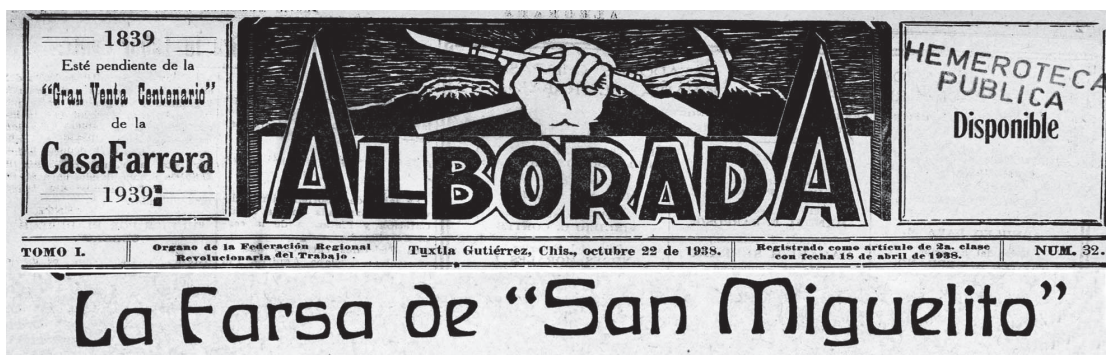

Por J. Erasmo CAMACHO.

Para borrar la creencia de los prar, que dicho individuo Urbina, le han depasitado un pueblo al piritus raquíticos; para quitar espiritus raquiticos; para qus de esa venda que cubre los ojos dejan arras los incautos que se dejan arrastrar por timadores que embaucan a mucha giente, porque así encuen tran su "modus vivendi"; voy a permitirme decir algo que esclarezca de una manera definitiva, la verdad aceo des hace algún Miguelito que de tiempo ha blevalo hacia gente en busca de aivio
los males que les aquejan

los males que les aquejan.
iSeñores, no nay tal San Miguel, iSeñores, no nay tal San Miguel, ni mucho menus espiritu divino con facultades curativas! El mis terio consiste únicamente en lo que a continuación relataré

Hace más o menos dos años, que al pueblo de Soyaló llegó un titiritero apellidado Legin de titirite cionalicad extranjera, quien tenia facultades de ventrilocuo, mediante cierta cantidad de dinero, enseñó al Sr. Guadalupe Urì na (fallecido), -descubridor d famoso "San Miguelito", el art de emitir un silbidito especial con el que fácilmente hizo creer que se trataba de la voz del santo me cionado.

Con este secreto y la no meno admirable idea que fluyó a su me te, viendo la ciega credulidad que aún impera en nuestro medio, creó su personaje bautizándolo con nombral de un s a n to, haciendo creer, que el dicho silbido peculiar, era emitido por él.

Al ver estos renglones, muchos de ustedes preguntarán: $i \mathrm{Y}$ por qué dan efecto algunas curacio nes? ¿Cómo es que receta cas puras medicinas de patente !L respuesta es concreta y clara: co ma es fácil ientender que en to
Jas aquellas enfermédades de or ge nnervioso, la sugestión es primordial factor para su curación; la gente mistica obsesiona da por la fe, hallaba hasta en un vaso de agua rel remedio de su ma! th cambio, aquellos individuos $\mathrm{ct}$ yas enfermedades eran motivadas por otras causas recibian del "San tito" instrucciones de tomar medicinas de patente. Hay que acla cocía - como parte integrante nombrarlo su dirigente? iSi estio de folletos que consiguió en ca la conseceuncia del proceder de iversas farmacias de la Repúbli los demás!

ca y del Exterior; en en esta for Después de haber hecho la an$\mathrm{ma}$, como se explica lel mecanis. terior aclaración, considero permo de toda esta farsa, y es así tinente que las Autoridades del como el autor de esta treta, po- Estado, tomen cartas en el asur. día dar hasta detalles más insig- to para evitar así, que se siga en nificantes como, precio, modo de gañando vilmente al pueblo, pues escritura, farmacia, calle y núme si bien es cierto, que no kxigen ro, es decir; (dirección completa cuota determinada, en cambio, ob para poderlas conseguir. tienen buenas utilidadeb de los $\mathrm{Si} f$ ú condenable la actitud que creen haber recuplerado su suming pur cor to se de ser bueno es aún la actitud de su sobrino Ro médicos, no deben neclesitar de! dolfo del mismo apellido, herede- "San Miguelito" para hacer sus ro del la "veta" de $\tan$ deseable curaciones, pues bien pudiera esmina, quien, de menos inteligen- tablecer su consultorio en cual-cia que su tío y de más ambición, quier parte y prestar su ayuda por determinada suma de dinero, la humanidad; porque con esa for ha vendido el secreto a otros qu ma de proceder, restan clientela á más inconscientes, que han ha a los médicos titulados, quela la vido sido a vir holgadamente, en contínuas costa de privaciones y de mucho "papalinas" y con música hastn abos de estudio y no engañando el fastidio. En donde han refle- al público con su chantaje; infrin jado su poca táctica y su mucho giendo también la Ley ien los arcinismo, es $;$ en la forma como han tículos están en contra de la Re. reproducido al San Miguelito, pues volución, pues aumentan el núm cada poseedor del secreto, ha pues ro de fańticos y mudran en to su negocio particular en el lu concienci del pueblo, etablecien gar de su residencia, y hacen re- do la duda y el desconcierto exi corridos periódicamente, autonom las personas sensatas que han acu brándose sacerdotes, facultados a dido a dichos pueblos para cer. ejercer todos los rituales de la ciorarse de tan absurdo instrumen Iglesia c o mo: bautizar, casar, to de timadores.

etc., etc., $\mathbf{y}$ así es como tenemos T'erminaré con un estribillo que a San Miguelito en Ixtacomitán de una manera expontánea acudiú

en manos del señor Félix Agui-- a mi mente, y dice así:

ar, curando micos $\mathrm{y}$ pericos, $\mathrm{m}$ tigando males, calmando bautizando herejes, uniendo der tinos, mientras tanto.... Ivenga acá el dinero de los pobres pars su propia beneficencia! A José Ramírez también con su cajita debajo del brazo $\mathrm{J}$ sus rituales de hipócrita, yendo do arriba-abajo con su residencia on Chavarria; a Je sús Rachit y Servin López (Pre sidente Mrnicipal) con su nerocio en Tapipula la inte senta. iSerá esta la manera de

San Miguelito San Miguelón nada tiene de Santito solo es para timación.

Tuxtla Gutiérrez, Chis., octu-bre 10 de 1938. 


\section{LAVERAAD DELSANIIITOMIILGROSO}

El señor Dr, don José III de la Fuente, nos hà en tregado para su publicación el siguieule documento:

En cumplimiento de un de, con calcetines. Su plática ber como Autoridad Sanita es realmente rústica pero no ria, como ciudadano y como la de un tonto, es de pasmoprofesionista, llevé adelante sa serenidad y algo taimado. profesionista, llevé adelante sa serenidad y algo taimado.
las a veriguaciones que los En su plática domina una las a reriguaciones que los $\begin{aligned} & \text { En su plática domina una } \\ & \text { Servicios Sanitarios Coordi- }\end{aligned}$ Servicios Sanitarios Coordi-
nados del Estado habian ini-
mi tío por a anor a la Humanados del Estado habian ini ciado, con respecto al escan daloso paso del santito médi
co que había en poder de los tó resultado de la visita es poder los tá resumida en el contenido (a) fo Urbina, imagen a la que ciudad de Chiapa de Corzo el público comenzó a impo- Estado de Chiapas, siendo nerle la cualidad de hablar. las 17 horas del dia doce de La Oficina de Salubridad so junio de mil novecientos bre la que estaba recayendo treinta y siete, fueron presen gran responsabilidad legal y tes en el salon de la Presila inmoderada censura de dencia Municipal el C. Dr. los no creyentes, por nuestra José M. de la Fuenle, Jefe tolerancia, culminó después Accidental de los Servicios de tomar las debidas precau Sanitarios Coordinados, Dr. ciones legales, en que hici. Antonio J. Muñoa, el C. Pre ciones lo mos compares al referido propietario de la imagen genio Molina y el señor Ro quien se aventuró hasta la dolto Urbina, quien fue citaCiudad de Tuxtla Gutiérrez, do previamente con el objeto con objeto según el mismo de interrogarlo y averigua de legalizar la escritura de la forma en que lleva a cabo propiedad de un terreno, y las curaciones que se di además hacerle una cajita, cen efectuadas por mediarulgarmente llamada nicho. c i ó $n$ d e u n a i m a g e n Su presencia en la Ciudad de en el pueblo de Soyaló, Dis Tuxtla Gutiérrez, produjo trito de Chiapa de este Esta una verdadera romería, lo do y que públicamente se ha que dió oportunidad a la po- venido propagando que dilicia de deterlo y ponerlo a cha imagen habla y receta. nuestra habla, en la Presiden Después de una exhortación cra Municipal de la vecinal que los ros Médicos Oficia población de Chiapa de Cor les hicieron al Sr. Urbina, zo, para donde logró escapar. éste explicó que tanto él como El día de ayer, en compañía su tío el Sr. Guadalupe Urbi del C. Notario Público Lic. na han estado medicinando José A. Mijangos, del perio- a muchas personas que los dista Jesús Anterio Cárdenas han llegadıs a solicitar, por y de un empleado de los Ser que tanto el exponente como y de un empleado de los Ser que tanto el exponente como vicios Sanitarios Coordina- su señor tio, son conocedodos, nos trasladamos a la res de yerbas y medicinas de Ciudad de Chiapa de Corzo patente y que, para hacer un a fin de interrogar al señor servicio a la humanidad $\mathrm{y}$ Rodolfo Urbina, y conocer la como prácticos, sin honora imagen a la que se atribuía rios de ninguna especie para faculdudes humanas.

la gente pobre, les prescriben ya sean medicinas de patente o yerbas que ellos conocen. Se le interrogo si por mediacion de la imagen que se tiene presente (la cual se describirá en esta acta,) es que efectuan las curaciones, contestando el Sr. Urbina q su tío mencionado es práctico en medicina y cuando é no se encuentra en Soyaló el exponente es el que atiende a los enfermos y suplica (Pasa a la 6a. pág.) aparentar extrema humil-

huaraches cubriendo sus pies

\section{La Verdad del San- tito Milagroso... \\ Viene de la $3 a$. página,} a los señores Médicos presen les que por amor a la huma nidad los dejen seguir curan do. Ambos Médicos le dieron a Urbina una amplia ex plicación de los derechos y deberes que tienen los que se dedican como prácticos a atender enfermos en los lu. gares en que no existen mé dicos titulados y que el obje to de este acto es solamente evitar toda mixtificación pero nunca el ejercicio de un derecho.

Al misıno tiempo se le die rón a conocer los rejuisitos que se necesitan llenar para ejercer como prácticos e 11 medicina según las leyes $1 \mathrm{e}-$ derales en vigor. Se lè exhor tó para que en lo sucesivo no emplee medios de mixtifica. ción o engaño al público en sus procedimientos de atención a los pacientes que a ellos acudan por ser, medi s reprobados por la moral tales como el empleo de im :genes a las que se atribuyen facultades humanas y otros por el estilo, pues esto está sancionado por la Ley, a lo que el señor Rodolfo Úrbina prometió no emplearlos en lo sucesivo, para lo cual no solicitará la devolución de la tantas veces referida es tampa en cuestión, pero su plica a los señores médicos que le escuchan, que si está en sus posibilidades, le ministren algunos medicamentos que pueda recetar a sus enfermos, prometiendo em plearlos en el ejercicio de su profesión, en Soyaló, sin ha cer uso de ninguna mixtifica ción, ofreciendo desde hoy distribuirlos gratuitamente a sus enfermos. El Sr. Dr. de la Fuente hace atenta in vitación al Sr. Urbina para que se acerque a las Oficinas de Salubridad en Tuxtla Gu tiérrez, en donde se le dará algunanas orientaciones y se le entregarán algunos meriicamentos y propaganda hi. giénica que solicita para disIribuirla en Soyaló y las ran cherias de este Municipio.

La imagen que ha servi in para las mixtificaciones y $y^{\prime}$ se tiene presente, es una co pia fotostática de un niño de Atocha, como de siete cenlímetros de largo, por cuatro de ancho, dentro de un camarín de madera, y que el público ha dado en llamar San Mrguelito. Intervienen en esta acta los Sres. Licenciado y Notario José A. Mi. jangos y Periodista Jisús Samperio Cárdenas, quicies también estuvieron presentes en todo este acto, además lel C. Secretario del Ayuntamiento de Chiapa de Corzo, con lo que se termina la presente que se levanta por cuadruplicado para los efectos legales. - Conste. Firmado: Dr. J. M. d e la Fuente L.-Eugenio Molina. - Rodolfo Urbina.-J. Anto nio Muñoa.-José A. Mijangos.-J. Samperio C. - Rúbri cas.-C. Alvarez. Secretario.

Con lo anterior, la actuación de los Servicios Sanita. rios Coordinados dió cumpli miento a las disposiciones relativas del Código Sanitario Federal vigente y a la sociedad presenta este material verídico para que juzgue como lo crea pertinente.

194 Revista LiminaR. Estudios sociales y humanísticos, año 7, vol. VII, núm. 2, diciembre de 2009, Tuxtla Gutiérrez, Chiapas, México. ISSN: 1665-8027 